\title{
Inherited thrombophilia in a patient with colorectal carcinoma
}

\author{
Matej Hrnčár ${ }^{1}$, Jozef Breznický ${ }^{2}$, Juraj Chudej ${ }^{3}$, Juraj Sokol ${ }^{3}$, Ján Staško ${ }^{3}$ \\ ${ }^{1}$ Department of Oncology, Faculty Hospital F.D. Roosevelt, Banská Bystrica, Slovakia \\ ${ }^{2}$ Department of Orthopaedics, Faculty Hospital F.D. Roosevelt, Banská Bystrica, Slovakia \\ ${ }^{3}$ Department of Haematology and Transfusiology, Jesseniuss Faculty of Medicine, Martin, Slovakia
}

Gastroenterology Rev 2020; 15 (2): 175-177

DOI: https://doi.org/10.5114/pg.2019.86746

\begin{abstract}
Address for correspondence: Matej Hrnčár MD, Department of Oncology, Faculty Hospital F.D. Roosevelt, St Namestie Ludvika Svobodu 1, 97401 Banská Bystrica, Slovakia, e-mail: mahrncar@gmail.com
\end{abstract}

Venous thromboembolism (VTE) is a serious clinical problem. Malignancies are a common cause of VTE, and at the same time venous thrombosis plays a role in the pathogenesis of cancer. The incidence of VTE in cancer patients is 4-6 times higher than in the general population. Approximately $20 \%$ of all VTE cases occur in cancer patients. The VTE is the second most common cause of death in cancer patients. Tumour incidence is highest in the first 6 months after VTE diagnosis. Approximately $40 \%$ of VTE patients have metastasis at the time of tumour diagnosis. Cancer patients with VTE have a worse prognosis than those with malignancy alone. The pathophysiology of the hypercoagulable state and VTE is multifactorial, depending on the type of tumour, its size, localisation, growth, stage of cancer, and the condition and interaction of tissues and organ systems with malignancy. Risk factors for VTE in cancer patients include, but are not limited to, active disease and the presence of metastases [1-3]. The most important risk factors for thromboembolic disease are congenital and acquired thrombophilia (Table I). Factors such as immobility, surgical treatment, central venous catheter, or bulky disease increase the risk of thromboembolism.

We report a 48-year-old man with a history of right knee surgery followed by a deep venous thrombosis at 30 years old. The patient works in administration, is hypersthenic, and an occasional smoker. In his family history there is a presence of fatal myocardial infarction (father). The second manifestation of thromboembolism was when he was 42 years old. He was sent for examination to an angiologist for gradual pain in the right leg area, which lasted for two days with moderate intensity without physical activity. The swelling on the right side of the ankle is permanent even with compression therapy and has not changed. Varix in the leg at the back is accentuated and sensitive to palpation. Duplex ultrasonography showed varicose phlebitis in the anterior system, and a deep venous system on the forefoot and on the thigh without signs of thrombosis. The patient is D-dimer positive. Low-molecular-weight heparin $(\mathrm{LMWH})$ anticoagulant treatment was initiated, with relief of symptoms. After a month, he is continuing with the regimen measures and with a compression bandage. Due to young age, we made a routine screening for malignancy - ultrasonography of abdomen, chest imaging, gastrofibroscopy and colonoscopy - all the tests were negative. Oncomarkers were negative, and congenital thrombophilic status was confirmed: homozygous factor $V$ Leiden and homozygous MTHFR C677T. Three months later while the patient was on a trip he had severe dyspnoea and chest pain, retrosternally localised. On ECG: right ventricular overload was seen - possible posterior myocardial infarction or pulmonary embolism. Computed tomography (CT) pulmonary angiographic examination did not confirm embolisation into the pulmonary artery. Confirmed subacute acute myocardial infarction inferoposterior, undergoes percutaneous transluminal angioplasty, on the coronary artery and stays on antiplatelet and hypolipidemic therapy. $\mathrm{He}$ is on cardiology and angiology dispensary every half year.

When he was 47-years-old, 17 years after the first manifestation of a thrombotic event, he was hospitalised for eneterorrhagia (during treatment with acetylsalicylic acid). Haemoglobin, platelet, and coagulation parameters are in normal range. When a colonoscopy was performed, there was a finding of a tumour about $30 \mathrm{~cm}$ from the anus - histologically moderately differentiated adenocarcinoma, grade II. After initial staging, $\mathrm{CT}$, which was negative for distant metastases, indicat- 
Table I. Classification of thrombophilia [1]

\begin{tabular}{|c|c|}
\hline \multicolumn{2}{|c|}{$\begin{array}{l}\text { 1. Primary/inherited - genetically determined propensity for } \\
\text { thrombosis }\end{array}$} \\
\hline \multirow[t]{2}{*}{ Common: } & Factor V Leiden (1691A) \\
\hline & Prothrombin 20210A (FII20210) \\
\hline \multirow[t]{3}{*}{ Less common: } & Deficiency of antithrombin III \\
\hline & Deficiency of protein C \\
\hline & Deficiency of protein $\mathrm{S}$ \\
\hline Rare: & Dysfibrinogenaemia \\
\hline \multicolumn{2}{|c|}{$\begin{array}{l}\text { 2. Secondary/acquired - factors or conditions present as } \\
\text { external stimuli that disrupt the haemostatic balance are } \\
\text { present }\end{array}$} \\
\hline \multicolumn{2}{|c|}{$\begin{array}{l}\text { a. Other diseases (arterial hypertension, diabetes mellitus, } \\
\text { atherosclerosis, hepatopathy, tumours, inflammation, } \\
\text { sepsis, nephrotic syndrome...) }\end{array}$} \\
\hline \multicolumn{2}{|c|}{ b. Physiological conditions (pregnancy, puerperium...) } \\
\hline
\end{tabular}

ed sigma resection. Laparoscopic low anterior rectal and sigma resection, post-operative prophylactic dose of LMWH in higher prophylactic dose. Five days after being released from hospital, the patient was re-hospitalised for eneterorrhagia, development of ischaemic colitis, and an abscess in the small pelvis. Surgical descendentomy, resection of colon sigomideum propter colitis ischaemica, toilette cavi abdominis, resectio omenti majus, drainage, initiated full anticoagulant treatment, clinically stabilisation, patient 1 week after second surgery released to home care. After consolidation he was sent to an oncologist, and from definitive histology, moderately differentiated (grade II) adenocarcinoma of the rectosigmoid colon penetrating into the muscularis propria, with three metastases to regional lymph nodes (10 examined) was diagnosed. Pathological staging pT2pN1. The CT staging showed no evidence of locoregional recurrence of underlying disease and no secondary focal changes. The patient was scheduled for post-operative capecitabine treatment - six cycles for risk parameters (lymph nodes, age, high proliferation index), but he refused infusional chemotherapy. During the second and third cycle of chemotherapy he had worsening phlebitis on right leg, with a significant reduction of mobility. He was treated with $\mathrm{LMWH}$ and antibiotics. He refused the fourth cycle because of intolerance. After 3 months he had a CT examination, which was negative in terms of dissemination or local recurrence, and colonoscopy was negative. Oncomarkers are negative, and we continue dispensary care.

The incidence of thrombotic complications in patients with malignancy is higher than in the general population. There are few data on the association of congenital thrombophilia with malignant disease. Most of the publications are small and the results are limited to geographic variability, tumour type, stage, and treatment. Some suggest the association of mutation of factor $V$ Leiden and the prothrombin G20210A with the pathogenesis of malignancy. There is also an association with thromboembolic disease and MTHFR C677T mutation. The issue of screening for congenital thrombophilia is currently unresolved, as well as a possible thromboprophylactic approach in these patients [4]. Battiselli et al., on a sample of 121 gastric cancer patients, suggested that the risk factors for thrombophilia are based on an acquired base rather than on the genetic background. The prothrombin mutation G20210A does not appear to be a cofactor in the pathogenesis of gastric cancer [5]. Curigliano et al. analysed the effect of prothrombotic factor $\mathrm{V}$ Leiden and prothrombin mutation G20210A on the development of deep venous thrombosis associated with central venous catheter in patients with locally advanced or metastatic breast cancer. A cohort of 300 patients demonstrated a high risk of catheter-associated deep venous thrombosis in these patients with factor $V$ Leiden chemotherapy [6]. Ingrid Pabinger et al. presented at the American Society of Haematology (ASH) annual meeting 2012 a poster in which where a study of over 900 patients showed the association of factor $\mathrm{V}$ Leiden with the risk of developing TECH in patients with malignancy, especially in patients with newly diagnosed malignancy [7]. Association in the pathogenesis of prostate carcinoma, lung carcinoma, and oral carcinoma with congenital thromboembolism polymorphisms has not been demonstrated [8-10].

Although there are few data on the association of congenital thrombophilia with malignant disease, in clinical practice there is a need for cancer screening in patients with thromboembolic disease and undetected direct cause or congenital thrombophilic status. In our patient, cancer screening did not play a role at the time of the first manifestation of thromboembolism, because cancer was diagnosed 17 years after the first manifestation. Thus, the question of widespread screening (here for colorectal carcinoma) is difficult to implement (false positivity of the test for occult bleeding). Individual small sets point to the possibility of linking thromboembolic disease with factor $\mathrm{V}$ Leiden mutation and prothrombin G20210A mutation in patients with malignancy. There is also an association with thromboembolic disease and MTHFR C677T mutation. The issue of screening for a congenital thrombophilic condition in newly diagnosed malignancy is currently unresolved, as well as a possible thromboprophylactic approach in these patients [4]. 
There is a need for more data about which patients would benefit from which type type of malignancy search, and especially to determine when to look for it. But we may not be able to answer this question in the near future, so we now have to focus on clinical experience and think about the possibility of cancer in patients with congenital thrombophilia. In the case of any suspicion, adequate investigation is needed to detect the early stage of the disease.

\section{Conflict of interest}

The authors declare no conflict of interest.

\section{References}

1. Kubisz P. Poruchy hemostázy. In: Hematológia a transfuziológia. Kubisz P, et al. Bratislava, Praha, Grada 2006; 159-216.

2. Chudej J, Mutácia protrombínového génu 20210A v zdravej populácii a u trombofilných stavov. Lek Obz 2011; 60: 155-61.

3. Matýšková M. Trombotické stavy. In: Neonkologická hematologie. Penka M, Buliková A, et al. Grada, Praha 2009; 157-63.

4. Horowitz N, Brenner B. Thrombophilia and cancer. Pathophysiol Haemost Thromb 2008; 36: 131-6.

5. Battistelli S, Stefanoni M, Genovese A, et al. Prevalence of factor $V$ Leiden and prothrombin G20210A in patients with gastric cancer. World J Gastroenterol 2006; 12: 4179-80.

6. Curigliano $G$, Mandalà $M$, Sbanotto A, et al. Factor V Leiden mutation in patients with breast cancer with a central venous catheter: risk of deep vein thrombosis. Support Cancer Ther 2006; 3: 98-102.

7. Pabinger I, Ay C, Dunkler D, et al. Factor V Leiden mutation increases the risk of venous thromboembolism in cancer patients - results from the Vienna Cancer and Thrombosis Study (CATS). J Thromb Haemost 2015; 13: 17-22.

8. Ghasemi S, Tavakoli A, Moghadam M, et al. Risk of prostate cancer and thrombosis-related factor polymorphisms. Biomed Rep 2014; 2: 53-6.

9. Savafl I. The frequency of factor $V$ Leiden mutation in patients with lung cancer. Turk Resp J 2003; 4: 113-5.

10. Vairaktaris E, Yapijakis C, Wiltfang J, et al. Are factor V and prothrombin mutations associated with increased risk of oral cancer? Anticancer Res 2005; 25: 2561-6.

Received: 15.04 .2019

Accepted: 19.06 .2019 